\title{
O valor da Comunicação Organizacional e das Relações Públicas
}

\author{
The value of Organizational Communication \\ and Public Relations
}

\section{El valor de la Comunicación Organizacional y de las Relaciones Públicas}

\section{Valéria de Siqueira Castro Lopes}

- Doutora e mestre pela Escola de Comunicações e Artes da Universidade de São Paulo (ECA-USP)

- Docente dos cursos de Relações Públicas da ECA-USP e da Faculdade Cásper Líbero

- Docente do curso de Pós-Graduação Lato Sensu de Gestão Estratégica em Comunicação Organizacional e Relações Públicas da ECA-USP

- Atuou na Assessoria de Comunicação do Metrô-Rio de Janeiro e na Pró-Reitoria de Extensão e Cultura da Universidade de São Paulo

- Graduada em Relações Públicas pela Universidade do Estado do Rio de Janeiro (UERJ)

- Vice-presidente de Planejamento da ABRP-SP

- Sócia-diretora da Consultoria Mistura Fina Comunicação Organizacional

- Autora de diversos capítulos de livros

- valeria@misturafinacomunicacao.com.br

\section{Guilherme Grandi}

- Doutorando em História Econômica na Universidade de São Paulo

- Mestre em Economia e graduado em Ciências Sociais pela Universidade Estadual Paulista (Unesp)

- Professor de Economia dos cursos de Relações Públicas e Rádio e TV da Faculdade Cásper Líbero

- Autor de diversos artigos em revistas especializadas e da pesquisa "Avaliação e mensuração em projetos de Relações Públicas: análise de dois modelos de valoração de resultado"

- Experiência de pesquisa em Economia, com ênfase em economia dos transportes, economia da informação e valoração de resultados em comunicação corporativa

-ggrandi@usp.br; prof_grandi@yahoo.com.br 
Apresentar resultados é imprescindível em organizações nas quais os processos de gestão se voltam para a demonstração de valor. Esse cenário tem exigido dos profissionais da Comunicação esforços para demonstrar o valor econômico da área. O capítulo discute a demonstração de resultados em Comunicação Organizacional e em Relações Públicas e sua contribuição ao alcance dos objetivos de negócio, partindo da delimitação conceitual dos termos "avaliação", "mensuração" e "valoração" para, em seguida, refletir acerca das limitações e das perspectivas de valoração a partir do estudo de ativos intangíveis.

PALAVRAS-CHAVE: COMUNICAÇÃO ORGANIZACIONAL • RELAÇÕES PÚBLICAS • VALORAÇÃO • ATIVOS INTANGÍVEIS

Abstract

Submit results is essential in organizations where processes turned to the cash value. This scenario has required communication effort professionals to demonstrate its economic value. The chapter discusses the demonstration of results in organizational communication and public relations and their contribution to the scope of business goals, building on the conceptual delimitation of the terms assessment, measurement and valuation to then reflect on the limitations and future prospects of valuation from the study of intangible assets.

KEYWORDS: ORGANIZATIONAL COMMUNICATION • PUBLIC RELATIONS • VALUATION • INTANGIBLE ASSETS

Resumen

Presentar resultados es esencial en las organizaciones donde los procesos de la gerencia se dan vuelta hacia la demostración del valor. Esta escena ha exigido de los profesionales de la comunicación esfuerzos de demostrar su valor económico. El capítulo discute la demostración de resultados en la Comunicación Organizacional y Relaciones Publicas y su contribución al alcance de los objetivos de negocio, el irse de la delimitación conceptual de los términos evaluación, mensuración y valoración para debater las limitaciones y las perspectivas de la valoración del estudio de activos intangibles.

PALABRAS CLAVE: COMUNICACIÓN ORGANIZACIONAL • RELACIONES PÚBLICAS • VALORACIÓN • ACTIVOS INTANGIBLES 
C ada vez mais as organizações adotam uma gestão orientada para a demonstração de valor, que se apresenta, atualmente, como o principal desafio para Comunicação Organizacional e Relações Públicas. Em outras palavras, não basta mensurar os resultados obtidos pela área, mas há que se demonstrar seu valor e sua contribuição para o negócio.

A demonstração de desempenho a ser apresentada pelas áreas de Comunicação Organizacional e de Relações Públicas é o efeito de suas ações sobre os relacionamentos, a imagem e a reputação corporativa, ativos considerados intangíveis. Portanto, como demonstrar o valor de bons relacionamentos se estes muitas vezes evitam que os públicos protestem, processem ou façam propaganda negativa? Como demonstrar o impacto de um comportamento que não ocorreu por causa da habilidade organizacional em gerenciar sua comunicação e seus relacionamentos? Ou como relacionar um comportamento favorável demonstrado por um público hoje com um bom relacionamento que vem sendo desenvolvido em longo prazo? As respostas podem estar no estudo dos ativos intangíveis.

\section{Avaliação e mensuração: definindo alguns conceitos}

A demonstração de resultados não pode ser discutida fora do contexto do planejamento estratégico, pois, além de ser fase inerente ao processo, a avaliação só poderá ser conduzida de maneira correta se for antecedida por um planejamento bem realizado. Isso significa o estabelecimento de um objetivo claro e mensurável, elemento facilitador da avaliação e da mensuração, uma vez que é ele que norteia tanto a execução do plano quanto a verificação de seus resultados ${ }^{1}$.

A revisão da literatura no campo da Administração, origem dos estudos sobre planejamento, indica que o uso do termo "avaliação" é dos mais variados e pode estar relacionado ao controle de resultados, à análise do desempenho e à identificação dos desvios dos objetivos estabelecidos.

Albuquerque (1981) e Blanco (2000) apresentam a avaliação e o controle como uma única etapa do planejamento estratégico, denominando-as "avaliação". Para o primeiro autor, a avaliação é a "autocrítica dos procedimentos e efeitos alcançados e, por meio de uma ação planejada, permite a manutenção do plano, bem como o aperfeiçoamento de ações posteriores" (ALBUQUERQUE, 1981, p. 83). Já para o segundo, a avaliação pode ser entendida como uma "etapa imprescindível para que se possa conhecer o curso de um plano. Essa fase do planejamento fornecerá dados ao gestor sobre os resultados obtidos e sua adequação aos esforços investidos, orientando novas ações" (BLANCO, 2000, p. 156).

1 Para detalhamento do assunto recomenda-se ver Anderson e Hadley (1999), bem como Galerani (2006). 
Em contrapartida, Tavares (2000) distingue avaliação e controle, apresentando-os como processos complementares. Para o autor, a avaliação estaria voltada à eficiência das ações; o controle, à verificação e correção do plano.

Em Comunicação Organizacional, o termo é utilizado de forma semelhante. Segundo Watson (2001), a avaliação pode ser definida de três formas distintas:

1. avaliação comercial, que é uma justificativa para gastos no orçamento;

2. avaliação de simples eficiência, que questiona qual programa vem sendo orientado por resultados e

3. avaliação da eficiência dos objetivos, que julga programas em termos de alcance de objetivos e resultados desejados.

De modo geral, observamos que a avaliação não pode ser dissociada dos conceitos de eficácia e eficiência, já que, segundo Oliveira (2002), a eficácia está voltada ao alcance de resultados pretendidos, enquanto a eficiência se resume à execução de uma tarefa, de maneira adequada, com uma relação satisfatória entre custos e benefícios.

Embora a revisão bibliográfica indique não haver menção da expressão "mensuração de resultados" como etapa do processo de planejamento, acreditamos que ela é uma de suas partes integrantes e que, portanto, pode ou não se diferenciar da avaliação.

Apropriando-nos do conceito de "controle" estabelecido por Tavares (2000) e considerando as definições de eficiência e eficácia propostas por Oliveira (2002), bem como as diferentes perspectivas apresentadas por Watson (2001) para o termo "avaliação", propomos que se faça uma distinção conceitual entre avaliação e mensuração:

Avaliação - etapa do processo de planejamento que verifica o desempenho de um plano previamente estabelecido e que se dá ao longo de seu processo de implementação em busca de possíveis ajustes. Equivale ao que Watson denomina simples avaliação.

- Mensuração - processo conduzido com o intuito de demonstrar os resultados obtidos por um programa, ou seja, de demonstrar que os objetivos inicialmente propostos foram alcançados de fato, o que aproxima esse conceito da definição de Ferreira (1995) para avaliação de caráter somativo. Corresponde ao que Watson conceituou como avaliação da eficácia dos objetivos.

- Verificamos, ainda, que não há na literatura menção do termo "valoração”, motivo pelo qual propomos adotá-lo para designar a contribuição econômica que um determinado setor ou programa traz à organização, isto é, seu retorno financeiro por meio da relação custo-benefício. O con- 
ceito sugerido corresponde ao que Watson (2001) define como avaliação comercial. A Figura 1 ilustra a definição apresentada e a relação que a mesma guarda com as diferentes formas adotadas por Watson para conceituar avaliação.

Figura 1 - Avaliação, mensuração e valoração: uma proposta conceitual

Fonte: Elaborada pelos autores.

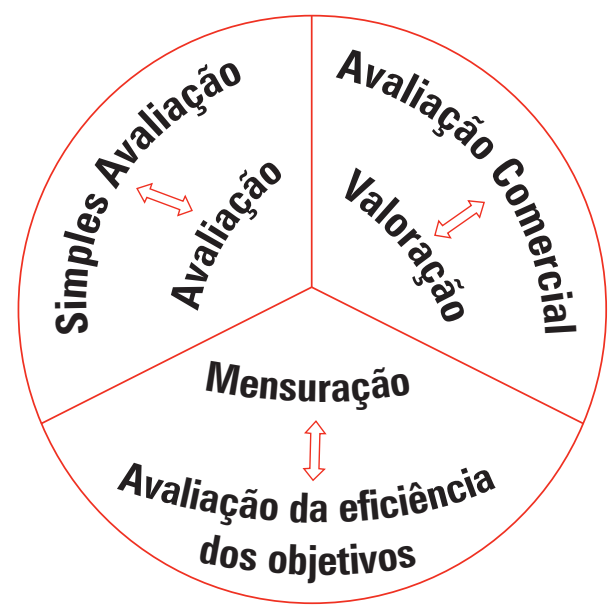

\section{0 balanced scorecard e a importância dos ativos intangíveis}

Os ativos intangíveis, normalmente excluídos dos balanços financeiros, têm-se mostrado importantes para a performance da organização como um todo, pois possuem a capacidade de criar valor no longo prazo, tanto em nível macro quanto microeconômico ${ }^{2}$ (KAPLAN; NORTON, 2004, p. 4), além de representarem uma vantagem competitiva sustentável e difícil de ser imitada pela concorrência. Por esses motivos, muitos acadêmicos e profissionais de administração e de finanças têm se preocupado com a mensuração do valor agregado pelos ativos intangíveis às organizações. O balanced scorecard (BSC) é uma das experiências desenvolvidas nesse campo com o propósito de auxiliar as empresas a administrarem seus ativos intangíveis.

Criado pelo consultor acadêmico Robert Kaplan e pelo principal executivo do Instituto Nolan Norton, David Norton, o BSC constitui um conjunto de

2 Observamos que as estratégias de criação de valor empregadas por cada empresa (nível microeconômico), se consideradas conjuntamente, isto é, em termos agregados, acabam contribuindo para níveis mais elevados de crescimento econômico dos países (nível macroeconômico). 
medidas de desempenho que serve de base para uma gestão estratégica. Ele permite às empresas acompanharem seu desempenho financeiro considerando tanto os ativos tangíveis quanto os intangíveis.

Nas experiências conduzidas por Kaplan e Norton (2004), os executivos que conheceram essa ferramenta de mensuração vislumbraram a possibilidade de utilizá-la na implementação de novas estratégias organizacionais, pois perceberam que a criação de valor por meio de ativos intangíveis não se encontra unicamente nos processos internos mas também na competição intra-setorial. Nesse sentido, o BSC transformou-se em uma ferramenta de gestão utilizada na busca pela excelência empresarial, justamente por conseguir identificar as estratégias que geram valor a uma organização por meio dos seguintes elementos (KAPLAN; NORTON, 2004, p. 7):

1. Desempenho financeiro - se formos bem-sucedidos, como seremos percebidos pelos nossos acionistas?

2. Sucesso com os clientes - para cumprir a visão organizacional, como devemos cuidar de nossos clientes?

3. Processos internos - para satisfazer os clientes, em quais processos devemos ser excelentes?

4. Aprendizado e crescimento - para realizar nossa visão, como a organização deve aprender e melhorar?

A perspectiva "aprendizado e crescimento" trata dos ativos intangíveis da organização e de seu papel na estratégia. Os ativos intangíveis são classificados em três categorias pelos autores:

- Capital humano - habilidade, talento e conhecimento dos empregados.

- Capital da informação - bancos de dados, sistemas de informação, redes e infraestrutura tecnológica.

- Capital organizacional - cultura, liderança, alinhamento dos empregados, trabalho em equipe e gestão do conhecimento.

O grande desafio de mensurar a contribuição dos ativos intangíveis decorre do fato de que o impacto causado por eles não é facilmente observável, dado que muitas vezes não se expressam em termos contábeis sobre os indicadores financeiros. Kaplan e Norton afirmam que as melhorias nos ativos intangíveis atingem os dados financeiros por via indireta, ou seja, por meio de "cadeias de relações de causa e efeito". Exemplificam os autores:

O treinamento dos empregados em gestão de qualidade total (TQM) e em técnicas de seis sigmas pode melhorar diretamente a qualidade dos processos. Esperase, então, que tais melhorias resultem no aumento da satisfação dos clientes que, por sua vez, deve reforçar a fidelidade dos clientes. Por fim, a fidelidade dos clientes acarreta o aumento das vendas e das margens, em consequência, de relacionamentos mais duradouros com os clientes (KAPLAN; NORTON, 2004, p. 31). 
Não há dúvida de que relacionamentos mais duradouros com os clientes implicam aumentos potenciais dos lucros no futuro, o que contribui positivamente para a expectativa de melhoria do desempenho econômico da empresa. Todavia, a criação de valor por meio de ativos intangíveis, da qual a reputação da marca detém hoje uma importância vital às empresas, difere sob alguns aspectos da criação de valor a partir da gestão de ativos tangíveis, físicos e financeiros.

O valor de um ativo intangível depende de seu alinhamento com a estratégia geral da organização. Ainda utilizando o exemplo dado sobre treinamento em técnicas de qualidade, os autores lembram que tal escolha tem maior valor para as organizações que possuem estratégia de baixo custo total do que para aquelas que adotam estratégia de liderança e inovação.

Os autores sugerem que uma estratégia cria valor para uma organização somente quando os indicadores de desempenho considerados estratégicos são encarados como conexões entre os componentes da estratégia geral de uma organização que, por sua vez, é representada por um mapa estratégico. Este último consiste, portanto, na conexão de objetivos que se estabelecem segundo uma relação de causa e efeito e, de acordo com os autores, deve ser construído considerando-se alguns princípios:

1. A estratégia equilibra forças contraditórias - o ponto de partida da descrição da estratégia é equilibrar e articular objetivos econômicos de curto prazo, como por exemplo aumento de produtividade, com objetivos de longo prazo de acréscimo consistente nos lucros.

2. A estratégia baseia-se em proposição de valor diferenciado para os clientes.

3. O valor é criado por meio dos processos internos - os processos internos estão relacionados à gestão operacional de uma organização e são uma das quatro perspectivas, anteriormente citadas, que auxiliam na criação de valor (aprendizado e crescimento, desempenho financeiro e sucesso com os clientes). Os processos internos são agrupados pelos autores da seguinte forma:

- Gestão operacional

- Gestão de clientes

- Inovação

- Regulatório e social

4. A estratégia compõe-se de temas complementares e simultâneos - cada agrupamento de processos internos fornece benefícios em diferentes momentos. Por exemplo, os resultados do fortalecimento dos relacionamentos com os clientes surge a curto prazo, enquanto os benefícios decorrentes do aprimoramento dos processos regulatórios e sociais podem ocorrer a longo prazo, à medida que as empresas evitam litígios e reforçam sua reputação na comunidade.

O modelo apresentado pelos autores pode ser apreendido na Figura 2. 
Figura 2 - 0 balanced scorecard e o processo de gestão estratégica

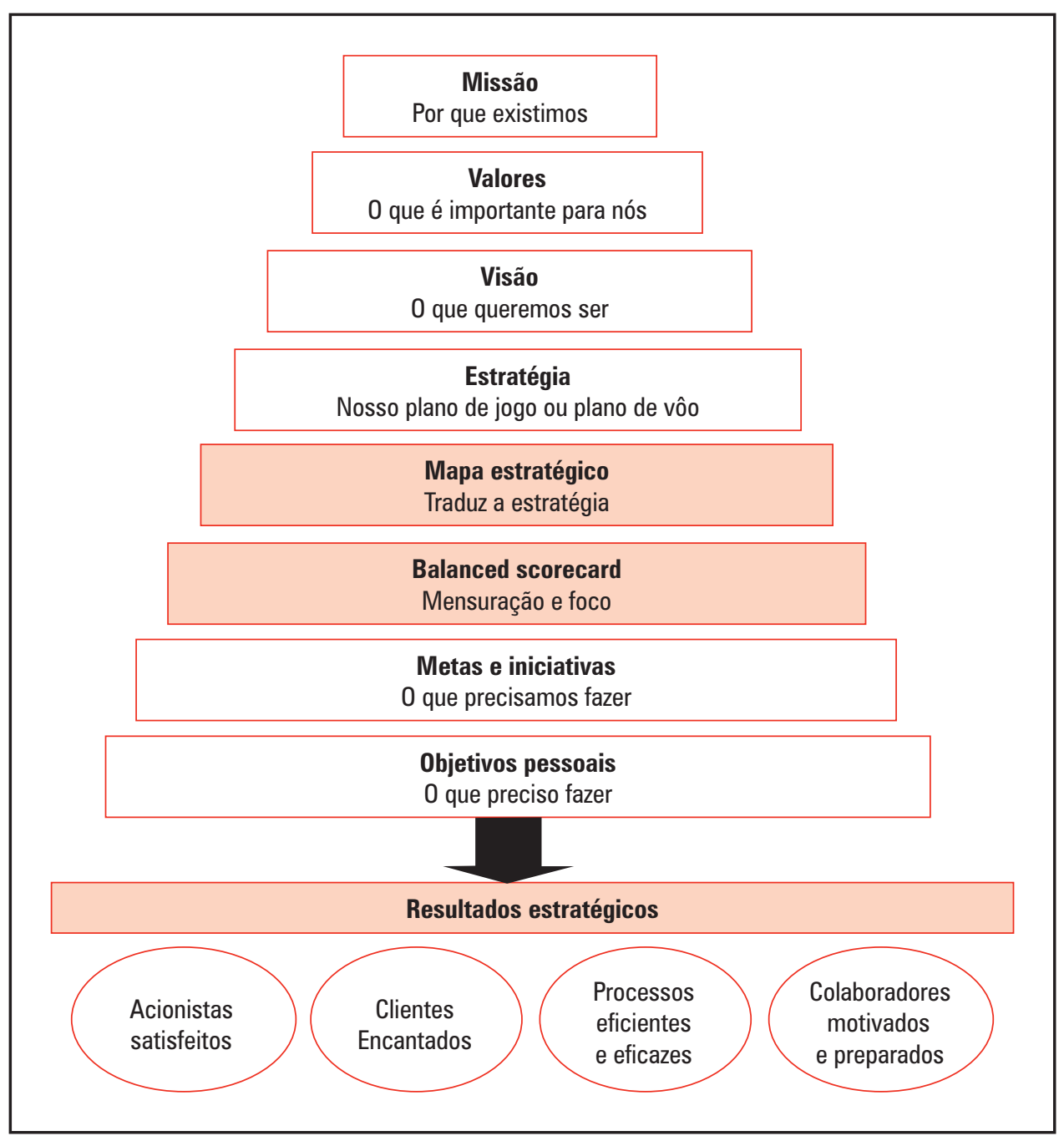

Fonte: Kaplan e Norton (2004, p. 35).

Contudo, entendemos que a abordagem dada aos ativos intangíveis pelo BSC fornece alguns parâmetros para que as áreas de Comunicação Organizacional e de Relações Públicas possam valorar seus resultados, os quais se encontram dentro dessa categoria de ativos. $O$ fato de os autores defenderem a mensuração de resultados dos ativos intangíveis em conjunto com os ativos tangíveis, desde que alinhados à estratégia geral, indica a necessidade de se identificar o impacto gerado pelas ações e pelos programas de Comunicação no desempenho de outras áreas e, consequentemente, o retorno trazido por eles à organização em seu desempenho final. 
O processo de gestão descrito por Kaplan e Norton (2004) na Figura 2, além de explicitar a necessidade de um planejamento estratégico organizacional para a adoção do BSC - uma vez que seu uso deve partir da missão, da visão, dos valores e da estratégia de negócios pré-definidos - indica resultados estratégicos condicionados aos relacionamentos com os stakeholders (acionistas, clientes e colaboradores), o que reforça a necessidade de a organização apresentar habilidades em relacionar-se e negociar com seus públicos de interesse, destacando a relevância da atividade de relações públicas. Neste ponto, Kaplan e Norton (2004) dialogam com Hon e Grunig (1999), que defendem como principal atividade de Relações Públicas a construção e o aumento dos relacionamentos de longo prazo com os públicos-chave de uma organização.

\section{A contribuição das Relações Públicas na geração de valor}

Segundo Hon e Grunig (1999), as organizações consideradas eficientes são capazes de alcançar o que pretendem, por escolherem, entre outros fatores, os objetivos que são valiosos para si e para seus públicos estratégicos. Por isso, a organização consegue minimizar os esforços dos públicos em interferir nas decisões organizacionais. A oposição dos públicos aos objetivos e às decisões organizacionais frequentemente resulta em problemas e crises, razão pela qual o processo de desenvolvimento e manutenção de relacionamento com públicos estratégicos é um componente crucial da administração estratégica e do gerenciamento de crises.

Pela diversidade de públicos, a tarefa de incorporar seus objetivos, interesses e preocupações no processo de decisão estratégica das organizações evidentemente não é fácil. Entretanto, as organizações geralmente tomam decisões melhores quando ouvem seus stakeholders, em vez de simplesmente tentar persuadi-los a aceitar os objetivos organizacionais após a resolução ter sido tomada. Essa postura garante um entendimento entre administração e públicos, diminuindo a probabilidade de se comportarem de forma a trazer consequências negativas aos interesses recíprocos.

Assim, a área de Relações Públicas torna-se fundamental para a eficácia organizacional quando é capaz de identificar os stakeholders como parte do processo da administração estratégica e conduzir os programas de Comunicação no sentido de desenvolver e manter relacionamentos de longo prazo entre a administração e esses públicos.

Entre os processos internos que envolvem a criação de valor, os processos regulatórios e sociais corroboram o que Hon e Grunig definem como o estabelecimento de relações estáveis e duradouras que permitem a existência da organização e a manutenção de um ambiente estável de negócios. Os processos regulatórios e sociais auxiliam as organizações a manter suas operações nas 
comunidades e nos países em que produzem e vendem, por meio da adequação de suas práticas à regulamentação nacional e local sobre o meio ambiente, a segurança e as relações de trabalho.

Com o objetivo de obter um desempenho que lhes proporcione reputação, muitas organizações - por meio de ações em áreas consideradas críticas, como meio ambiente, segurança e saúde, práticas trabalhistas e investimentos na comunidade - propõem ir além das obrigações mínimas impostas por lei. Dessa forma tais empresas atraem e retêm empregados de alta qualidade, tornando os processos de recursos humanos mais eficazes e eficientes; reduzem os acidentes ambientais; e melhoram a segurança e saúde dos empregados, aumentando a produtividade e reduzindo os custos operacionais.

Além disso, as empresas com imagem positiva e reputação notável geralmente desfrutam de ótima imagem perante os clientes e os investidores socialmente conscientes, fato este que denota uma estreita relação entre os propósitos das Relações Públicas, o que Pruzan (2001, p. 57) denomina uma gestão de perspectiva reflexiva:

Felizmente, há um aumento no número de organizações que estão focando os valores não simplesmente para proteger a imagem corporativa e sua 'licença' de operar em situações de crise. Há uma perspectiva que está tomando lugar da perspectiva de um stakeholder (os acionistas), de um valor (o monetário): a perspectiva dos propósitos corporativos, uma perspectiva inclusiva, de multistakeholders e multivalores.

Essas conexões com os objetivos de recursos humanos, de operações, de clientes e de finanças demonstram como a gestão eficaz do desempenho regulatório e social é capaz de impulsionar a criação de valor no longo prazo, uma vez que as organizações conseguem evitar conflitos, obtendo, com isso, uma imagem de boas empregadoras, fornecedoras e parceiras ${ }^{3}$.

As organizações que enfatizam a perspectiva pragmática, ou seja, que estão focadas na racionalidade econômica, em bons resultados financeiros, no sucesso em vez da inclusão ou do envolvimento - focos de atuação da perspectiva reflexiva -, normalmente questionam a existência e os resultados obtidos por áreas que possuem maior dificuldade em demonstrar resultados contábeis, como a Comunicação, em especial sua vertente institucional. Essa visão é puramente instrumental e

3 Não se pode descartar a possibilidade de tais ações serem conduzidas por uma organização que possua apenas o propósito de cumprir os padrões mínimos das legislações ou, até mesmo, alcançar imagem e reputação diante de seus stakeholders sem preocupar-se com a equivalência dos valores e objetivos organizacionais. Entretanto, não se pode desconsiderar que governos e sociedades têm exigido prestação de contas por meio de balanços sociais e ambientais e que, se a organização não apresentar um desempenho satisfatório nesses âmbitos, pode colocar em risco a própria capacidade de operar, crescer e fornecer valor futuro aos seus acionistas. 
presume que o real objetivo da organização é maximizar seus ganhos e que a administração deve ser avaliada somente pelo critério do lucro - um posicionamento que está em total oposição ao conceito inclusivo fornecido pela perspectiva reflexiva, que considera as organizações não apenas como máquinas de fazer dinheiro, mas como grupos sociais que possuem obrigações tal como os indivíduos e que seu comportamento afeta aqueles que se envolvem com elas. Esses públicos possuem valores que são mensurados pelo seu próprio direito, os quais a organização tem a obrigação de promover. Somente com esse argumento, a perspectiva reflexiva poderá responder de uma forma afirmativa à questão “esta ação se pode pagar?” (PRUZAN, 2001, p. 59).

Para reforçar sua posição, Pruzan menciona o estudo desenvolvido por Collins e Porras (1994, apud PRUZAN, 2001, p. 60) com empresas americanas fundadas no século XIX e que são consideradas até hoje as melhores em seus setores, organizações perenes e de marca corporativa altamente valorizada, motivos pelos quais os autores as denominaram empresas visionárias.

Essas empresas possuem valores centrais que são a razão fundamental de sua existência e que não são apenas divulgados mas alcançaram o estágio que transcende qualquer líder individual e perpassa toda a organização. Essas organizações não vivem só para os resultados financeiros, o que reforça o significado da perspectiva reflexiva e a influência da cultura corporativa na valorização da Comunicação como área estratégica, bem como na intensidade da pressão exercida pela administração sobre os profissionais da área por demonstração de resultados.

A possibilidade de as duas perspectivas, pragmática e reflexiva, coexistirem em uma organização é defendida por Pruzan (2001) como solução para tal impasse. Entretanto, o desafio de demonstrar o valor de algumas áreas, como a de Comunicação, permanece, cabendo aos acadêmicos e profissionais do campo a tarefa de suplantá-lo em conjunto.

\section{A valoração em Comunicação Organizacional e Relações Públicas: perspectivas metodológicas}

Com base na discussão feita nas seções anteriores, notamos que as estratégias consistem em ações a serem implementadas no decorrer de um período pré-estipulado, e a maneira de mensurar a eficácia dessas estratégias se resume, basicamente, a medidas de retorno dos investimentos.

As técnicas mais adequadas para se avaliar o sucesso ou fracasso de um investimento (entendido aqui como um programa da área de Comunicação Organizacional) são aquelas baseadas em fluxo de caixa descontado. Uma delas é a taxa interna de retorno do investimento. Por essa técnica, um programa comunicacional é julgado aceitável quando apresentar uma taxa de retorno 
maior do que as taxas de outras opções de investimentos concorrentes no mercado $^{4}$. Seu cálculo envolve distribuir no tempo todos os fluxos de caixa desse programa, contendo saídas e entradas de caixa geradas pela atividade corriqueira da empresa, com base em uma taxa de juros de desconto ajustada ao risco do projeto. Com efeito, essa técnica alinha-se diretamente ao objetivo de maximização do valor das empresas, na medida em que o retorno de um dado projeto representa o valor adicionado ao valor original da empresa, isto é, o acréscimo desejado pelos acionistas.

Convenientemente, a taxa interna de retorno, em função de suas limitações intrínsecas a toda e qualquer técnica de valoração, incorpora apenas as ponderações e os pesos relativos dos rendimentos, custos e despesas com capital em cada ano, fornecendo o valor aproximado do programa comunicacional ao final de cada período. Em outras palavras, tal taxa corresponde à proporção "média" da lucratividade desse investimento, durante um dado período, quando seu valor presente é zero ${ }^{5}$. Matematicamente, temos:

$$
V P=-V_{i}+\sum_{t=0}^{T} \frac{\left(R_{t}-C_{t}-I_{t}\right)}{\left(1+r_{i}\right)^{t}}+\frac{V_{F}}{\left(1+r_{i}\right)^{T}}
$$

Na fórmula, VP é o valor presente do programa comunicacional; $V_{I}$ é o valor inicial do programa pago à vista; $R$ são os rendimentos operacionais da empresa em cada ano; $C$ são os custos operacionais; I são as despesas com capital; ${ }_{t}$ é a subscrição do tempo indicando o ano de operação; $T$ designa o último ano do período considerado; $V_{F}$ é o valor final agregado à empresa ao final do período, e $r_{i}$ é a taxa de retorno.

Essa técnica de valoração considera que as operações empresariais detêm valor e que, por sua vez, este corresponde ao valor das projeções dos fluxos de caixa livres (free cash flows), descontado seu valor presente. Consideremos, então, o resultado operacional da empresa depois de deduzidos todos os impostos, mais custos que não envolvem caixa (por exemplo, a depreciação dos equipamentos), menos investimentos em capital de giro operacional, ativos imobilizados, dentre outros ativos. Dessa maneira, os fluxos de caixa livres refletem o caixa disponível em relação a todas as fontes de financiamento da empresa, isto é, na forma tanto de ações quanto de dívidas. Tais fluxos de caixa também podem ser considerados a expressão contábil da soma dos fluxos pagos ou recebidos de todas as fontes de capital (juros, dividendos, empréstimos, amortizações e pagamentos de dívidas etc).

4 Geralmente, os investidores consideram como taxa de rentabilidade padrão, para fins de comparação, a taxa de retorno proporcionada pelos investimentos atrelados à rentabilidade dos títulos públicos.

5 Para um detalhamento maior sobre as técnicas matemáticas referentes às taxas de retorno, ver Stauffer (1971). 
Segundo Young e O’Byrne (2003), a forma de aferição dos resultados econômicos, como a proposta acima, depende da análise dos chamados drivers financeiros. Entretanto, Martin, Mineta e Nakamura (2005, p. 218) observam que,

conforme a teoria de criação de valor, os drivers financeiros por si sós não explicam o processo de criação de valor das empresas. São variáveis que estão relacionadas mais à situação corrente da empresa. Outras variáveis, denominadas drivers não-financeiros, embora muito importantes para justificar o valor de mercado das empresas, não estão contidas nas demonstrações financeiras que são publicadas.

Percebemos nitidamente que esses direcionadores de valor não-financeiros se referem aos ativos intangíveis que, como já dissemos, são ativos que dificilmente se expressam por meio de dados contábeis. Martin, Mineta e Nakamura (2005, p. 219) afirmam, por exemplo, que o capital humano é um ativo que não figura nos balanços empresariais mas representa um valor investido que gera retorno operacional. Seu tratamento não se dá por critérios contábeis, porém representa uma grande fonte geradora de vendas e resultados. Os autores também propõem uma possível categorização desses drivers não-financeiros: qualidade dos produtos e serviços, satisfação do cliente, eficiência dos processos, inovação de produtos e processos, ambiente competitivo, qualidade e independência da gestão, administração de recursos humanos, remuneração de executivos e responsabilidade social.

Não há duvidas de que a questão central da mensuração dos resultados econômicos nos remete à forma de considerar os custos das empresas. Tratando-se de valoração, o conceito de custo a ser utilizado é o de custo de oportunidade, que considera tanto os custos explícitos (aqueles que exigem desembolso de moeda) quanto os implícitos (aqueles que não exigem gastos monetários mas devem ser considerados em sua relação custo-benefício nos momentos de tomada de decisão). Diferentemente do custo contábil (atrelado apenas aos custos explícitos), o custo de oportunidade consegue captar melhor os atributos das vantagens econômicas por atrelar-se, indubitavelmente, aos conceitos de eficácia e eficiência já anteriormente discutidos.

Nesse sentido, a taxa de desconto (uma taxa de juros qualquer do mercado) que incidirá sobre os fluxos de caixa livres das empresas deverá refletir o custo de oportunidade de cada fonte de capital, de acordo com a ponderação de cada tipo de fonte em relação ao capital total da empresa. Partindo dessas orientações metodológicas, podemos notar que, para os investidores que financiam um programa comunicacional de determinada empresa, o custo de oportunidade equivalerá ao retorno esperado advindo de outros investimentos com graus de risco semelhantes, já que, por definição teórica, o custo de oportunidade é o custo daquilo de que se abre mão dada uma tomada de decisão a respeito das várias opções de investimento (COPELAND; KOLLER; MURRIN, 2000, p. 125).

Já para a avaliação de projetos comunicacionais vinculados à área específica de Relações Públicas, Kim (2001) constrói um modelo econométrico compos- 
to por duas fases (ou etapas), o qual consiste em testar duas hipóteses que se autocorrelacionam ${ }^{6}$. Evidentemente, a reputação é a variável-chave desse modelo para se investigar o resultado das atividades das Relações Públicas e, portanto, a primeira hipótese testada por Kim refere-se à relação entre os investimentos feitos na área (ou subárea) de Relações Públicas e o seu impacto na reputação da empresa, seja esta qual for. Já o teste da segunda hipótese permite ao autor avaliar em que medida os resultados advindos da melhoria na reputação contribuem para o alcance dos objetivos centrais das empresas; em outras palavras, investiga-se qual foi o resultado econômico (o retorno) da reputação sobre a receita empresarial.

Kim trabalha com o conceito de reputação segundo a perspectiva de Grunig, Grunig e Ehling (1992), para os quais as ações eficientes em Relações Públicas são aquelas que pressupõem a construção de bons relacionamentos entre a organização e o seu público estratégico, o aumento de conhecimento por parte dos funcionários, a execução dos objetivos organizacionais, a influência legislativa, a disseminação de mensagens corretas etc. Não obstante, para esses autores, não se podem confundir os objetivos das Relações Publicas com as metas organizacionais, apesar dos primeiros se vincularem intrinsecamente aos resultados alcançados pelas organizações.

Por meio de equações lineares e não-lineares, Kim (2001, p. 6-7) encontrou, em um outro estudo, uma correlação positiva da reputação de 92 companhias (entre onze setores da indústria) com seus respectivos desempenhos econômico-financeiros. Para reforçar essa constatação, o pesquisador utilizou uma técnica de mensuração denominada modelo de equações estruturais, que lhe permitiu inferir a respeito da relação causal entre os gastos com Relações Públicas e os retornos financeiros.

A estrutura desse modelo pode ser sintetizada da seguinte maneira: os gastos com Relações Públicas configuram uma variável latente, isto é, uma variável oculta (ou não-observada) identificada por estimativas, a qual, por sua vez, se mostra fundamental para explicar a variável dependente denominada reputação. Na segunda fase do modelo, a reputação passa de variável dependente a independente ao explicar os retornos das companhias, que, paralelamente, também sofrem a interferência de uma outra variável exógena - o market share (KIM, 2001, p. 9-10). As duas fases desse modelo econométrico podem ser expressas matematicamente pelas equações (1) e (2).

$$
R_{i}=\square_{1}+\square_{2} \stackrel{(1)}{G R P_{i}}+u_{i}
$$

6 De acordo com Kendall e Buckland (apud GUJARATI, 2000, p. 401-402)., a autocorrelação pode ser definida como "correlação entre membros de séries de observações ordenadas no tempo [como em uma série temporal] ou no espaço [dados de corte]". Em outros termos, os eventos (ou as observações) referentes à primeira hipótese interferem nos eventos relacionados à segunda hipótese. 
$R$ é a variável dependente "reputação"; GRP é a variável independente latente "gastos com Relações Públicas"; $\square_{1}$ e $\square_{2}$ são parâmetros desconhecidos, porém fixos, chamados de coeficientes de regressão; $u$ é uma variável aleatória não-observável, também conhecida como termo de erro estocástico ou perturbação estocástica ${ }^{7}$; é a subscrição que designa o tamanho da amostra em termos de números de empresas analisadas.

$$
F_{i}=\square_{1}+\square_{2} R_{i}+\square_{3}^{(2)} M S_{i}+u_{i}
$$

$F$ é a variável dependente "retorno financeiro"; $R$ é a variável independente "reputação", anteriormente estimada na equação (1); MS é a variável independente "market share" (participação no mercado); $\square_{1}, \square_{2}$ e $\square_{3}$ são parâmetros desconhecidos, porém fixos, chamados de coeficientes de regressão; $u \mathrm{e}_{i}$ assumem os mesmos significados da equação (1).

Com base na pesquisa anual realizada pela revista Fortune, a respeito das quinhentas corporações mais bem-sucedidas, Kim pôde aferir, por meio de dados orçamentários, qual a magnitude dos gastos das empresas com as atividades de Relações Públicas. Além disso, é importante observarmos que a definição do autor para tais gastos parte da combinação de duas outras definições: uma presente no estudo O'Dwyer's Directory of Corporate Communications (1998) e outra derivada do trabalho de Troy (1993). Em suma, a definição de gastos com Relações Públicas de Kim vincula-se a oito categorias de atividades: relacionamento com a mídia e a imprensa; comunicação com os funcionários; relacionamento com a comunidade local; negociações com os governos local e federal; atividades de preservação ambiental; relacionamento com investidores, inclusive acionistas e a comunicação com Wall Street; contribuições; e publicidade corporativa (KIM, 2001, p. 12).

Dado o pressuposto de que todos esses gastos têm por objetivo a melhoria da reputação empresarial, o pesquisador também selecionou alguns critérios informacionais para se chegar a uma medida mais confiável de reputação. Oito atributos (critérios) foram investigados: qualidade de gestão; qualidade de produtos e serviços; habilidade de atrair, desenvolver e manter pessoas talentosas; valor como investimento de longo prazo; utilização de ativos tangíveis e intangíveis; bom uso dos recursos financeiros; inovação em cultura corporativa; e responsabilidade ambiental e comunitária (a respeito dos atributos da reputação corporativa, ver também Belch e Belch, 1995, p. 542).

De uma população de 476 empresas, 165 responderam aos questionários e 8 se recusaram a disponibilizar determinadas informações ou forneceram informações incompletas. Após o arrolamento dos dados, 157 empresas foram anali-

70 termo de perturbação estocástica u é um substituto de todas as variáveis omitidas do modelo que se comportam de forma aleatória, mas que coletivamente afetam a variável dependente. 
sadas, uma amostra equivalente a $33 \%$ do universo das empresas selecionadas. Dessas empresas, $40,8 \%$ atuam no setor terciário da economia e $59,2 \%$ no setor manufatureiro. Além disso, 57,3\% (ou 90 empresas) têm seus negócios focados na produção de bens de consumo, enquanto que $42,7 \%$ (ou 67 empresas) vinculam-se ao mercado de bens intermediários ou bens de capital (KIM, 2001, p. 14).

A estrutura orçamentária analisada por Kim denota que, em relação aos programas de Relações Públicas, 84 empresas (53,5\%) investem mais em atividades ligadas à Comunicação Interna e outras 68 empresas (43,3\%), mais na terceirização dos serviços relacionados aos programas de Relações Públicas por meio da contratação de agências externas. $O$ fato é que, em geral, o montante gasto com as Relações Públicas é extremamente significativo (KIM, 2001, p. 14-15).

O estudo de Kim propõe uma forma diferenciada de analisar o impacto econômico dos programas comunicacionais em relação aos objetivos de negócio pré-definidos no planejamento estratégico. Observamos que todas as variáveis utilizadas no modelo foram validadas por meio de testes estatísticos de significância. Os oito atributos selecionados pelo autor, a respeito da reputação, apresentaram índices expressivos de confiabilidade que representam o poder explicativo dos investimentos em Relações Públicas sobre as variáveis observadas. Paralelamente, $55 \%$ a $95 \%$ de todos os indicadores observados foram corroborados pela variável "reputação" estimada por $\operatorname{Kim}(2001$, p. 16). Em suma, comprovou-se por meio de técnicas estatísticas que existe uma correlação positiva entre os investimentos em Relações Públicas e a reputação empresarial, que, por sua vez, também afeta de maneira positiva o principal objetivo de toda e qualquer corporação, a aumento sustentável dos lucros.

\section{Considerações finais}

Embora haja por parte dos gestores organizacionais uma demanda por demonstração de resultados em curto prazo, o valor da Comunicação Organizacional e das Relações Públicas constitui-se, basicamente, de resultados passíveis de constatação somente em cenários espaciotemporais mais longos. Nesse sentido, observamos a necessidade de se monitorar constantemente a dimensão microeconômica do valor dessas áreas para que se possa verificar em que medida esses resultados auxiliam na consecução dos objetivos de negócio de longo prazo.

Consideramos que o papel desempenhado pela Comunicação na estrutura organizacional seja fator determinante para a escolha e aplicação do método de mensuração mais adequado às expectativas de atuação da área. Para que as técnicas de valoração propostas na seção anterior do texto sejam implementadas, há a necessidade de a área de Comunicação ter acesso incondicional às informações sobre a situação econômico-financeira da organização, bem como sobre o desenvolvimento de suas atividades administrativas e operacionais. Isso será possível apenas em organizações nas quais a área assume caráter 
estratégico, isto é, participando e interferindo no planejamento estratégico e na gestão do negócio.

Entendemos que o trabalho conjunto entre as áreas de Comunicação, de Finanças e de Contabilidade se torna imprescindível para que as dificuldades encontradas pelos profissionais de comunicação na valoração de resultados possam ser suplantadas. Por outro lado, devemos considerar que as práticas de valoração já são uma rotina em outras áreas da Comunicação, por exemplo, na Comunicação Mercadológica, que mede sua contribuição à organização por meio do valor adicionado à empresa pelas marcas que compõem o portfólio de negócios.

Considerando os objetivos bem como as especificidades que envolvem cada uma das áreas de Comunicação, propomos uma categorização dos efeitos gerados pelos variados programas de Comunicação Organizacional. Portanto, independentemente da área em foco, devemos selecionar a técnica mais adequada para mensurar os resultados dos programas que deverão ser analisados com base nas perspectivas de efeito direto, indireto e induzido.

Por efeito direto, entendemos aquela dimensão dos resultados mais facilmente observável, portanto de mais fácil mensuração, e que diz respeito inequivocamente à implementação e avaliação de um único programa ou ação comunicacional, como o número de contratos realizados com prospects resultante da participação de uma empresa em uma feira de negócio.

O efeito indireto é a dimensão dos resultados que corresponde à colaboração da área para o alcance dos macro-objetivos organizacionais. Por exemplo, o objetivo central de toda e qualquer empresa privada - o aumento consistente dos lucros - pode ter sido alcançado durante um determinado período em consequência não apenas da implementação de um programa comunicacional mas em razão de um conjunto de ações coordenadas com outras áreas estratégicas. Em outras palavras, significaria um esforço em demonstrar que a melhoria do clima organizacional e o consequente aumento da produtividade é resultado apenas dos esforços de comunicação. Na realidade, o índice de aumento na produção deve-se a um conjunto de ações conduzidas não somente pela Comunicação como também por outras áreas, entre elas a de Recursos Humanos. Vale ressaltar que a mensuração dessa dimensão dos resultados deve ser conduzida de forma agregada, ou seja, só será possível por meio da aplicação de medidas globais, a exemplo do Economic Value Added (EVA), que permitem apreender o valor adicionado ao negócio em sua totalidade, sem que se possa isolar a contribuição de uma determinada área.

Já o efeito induzido é a dimensão dos resultados que consiste na exata contribuição da área em foco com respeito ao alcance dos macro-objetivos organizacionais. A aferição desse tipo de efeito só é possível por meio de técnicas de valoração dos resultados de uma determinada área em contribuição ao negócio, uma vez que tal dimensão corresponde ao valor agregado à organização pela atuação específica desta. O modelo proposto por Kim (2001) se enquadra nessa categoria. 
Diante do exposto, esperamos que este artigo tenha contribuído não só para a discussão sobre a mensuração e a valoração de resultados em Comunicação Organizacional e Relações Públicas, mas sobretudo para o incentivo de outros trabalhos, tanto no âmbito acadêmico quanto no profissional, no desenvolvimento de metodologias que possam ser aplicadas, fortalecendo, dessa forma, ainda mais os campos da Comunicação Corporativa e das Relações Públicas.

\section{Referências}

ALBUQUERQUE, Adão Eunes. Planejamento de relações públicas. Porto Alegre: Acadêmica, 1981.

ANDERSON, Forrest W.; HADLEY, Linda. Guidelines for setting measurable public relations objectives. Gainesville: University of Florida, Institute for Public Relations, 1999. Disponível em: < http://www.instituteforpr.com/measurement_and_evaluation. phtml>. Acesso em: jul. 2006.

BELCH, George E.; BELCH, Michael A. Introduction to advertising \& promotion: an integrated marketing communication perspective. Chicago: Irwin, 1995.

BLANCO, Lorenzo. El planeamiento: práctica de relaciones públicas. Buenos Aires: Urgerman Editor, 2000.

COPELAND, Tom; KOLLER, Tim; MURRIN, Jack. Avaliação de empresas - valuation: calculando e gerenciando o valor das empresas. São Paulo: Makron Books, 2000.

FERREIRA, Aurélio Buarque de Holanda. Dicionário Aurélio básico da Língua Portuguesa. São Paulo: Editora Nova Fronteira, 1995.

GALERANI, Gilceana S. Moreira.Avaliação em comunicação organizacional. Brasília: Embrapa - Assessoria de Comunicação Social, 2006.

GRUNIG, Larissa; GRUNIG, James; EHLING, William. What is an effective organization? In: GRUNIG, James et al. (Ed.). Excellence in public relations and communication management. Hillsdale, N. J.: Erlbaum, 1992.

GUJARATI, Damodar N. Econometria básica. São Paulo: Pearson Education do Brasil, 2000.

HON, Linda Childers; GRUNIG, James. Measuring relationship in public relations: a report of the commission on public relations measurement and evaluation. Gainesville: University of Florida, Institute for Public Relations, 1999. Disponível em: <http:// www.instituteforpr.com/measurement_and_evaluation.phtml >. Acesso em: out. 2003.

KAPLAN, Robert; NORTON, David. Mapas estratégicos - Balanced scorecard: convertendo ativos intangíveis em resultados tangíveis. Trad. de Afonso Celso da Cunha Serra. Rio de Janeiro: Elsevier, 2004.

KIM, Yungwook. Measuring the economic value of public relations. Journal of Public Relations Research, New Jersey, v. 13, n. 1, p. 3-26, 2001.

KIRBAN, lloyd. showing what we do makes a difference. Public relations quarterly, new york, v. 28, n. 3, p. 22-27, 1983.

MARTIN, Diógenes M. L.; MINETA, Roberto K. N.; NAKAMURA, Wilson T. Determinantes financeiros de criação de valor das empresas brasileiras: um estudo empírico. In: SALAZAR, José N. A. (Org.). Tópicos avançados em finanças no Brasil. Campinas: Alínea, 2005.

O'DWYER'S Directory of Corporate Communications. New York: J. R. O'dwyer Co. 1998.

OLIVEIRA, Djalma de Pinho Rebouças. Planejamento estratégico: conceitos, metodologia e práticas. 18. ed. ver. e ampl.. São Paulo: Atlas, 2002.

PRUZAN, Peter. Corporate reputation: image and identity. Corporate Reputation Review, London, v. 4, n. 1, p. 50, Spring 2001.

STAUFFER, Thomas R. The measurement of corporate rates of return: a generalized formulation. Bell Journal of Economics and Management Science, v. 2, n.2, 1971.

TAVARES, Mauro Calixta. Gestão estratégica. São Paulo: Atlas, 2000.

TROY, K. Managing corporate communication in a competitive climate (Report n. 1023). New York: Conference Board, 1993.

WATSON, Tom. Integrating planning and evaluation. In: HEATH, Robert L. Handbook of public relations. Thousand Oaks, California: Sage, 2001.

YOUNG, David S.; O'BYRNE, Stephen F. EVA e gestão baseada em valor: guia prático para implementação. Porto Alegre: Bookman, 2003. 